\title{
A dimensão interdiscursiva do dizer na escrita científica: o diálogo com a palavra de outrem em artigos científicos de jovens pesquisadores ${ }^{1}$
}

\author{
José Cezinaldo Rocha Bessa² \\ Programa de Pós-Graduação em Letras e Programa de Pós-Graduação em Ensino, \\ Universidade do Estado do Rio Grande do Norte, Pau dos Ferros, RN, Brasil
}

Resumo: Considerando que os pesquisadores podem desenvolver maneiras sutis e complexas de elaborar as palavras dos outros (BAZERMAN, 2011) na escrita de textos acadêmicocientíficos, pretendemos examinar, neste trabalho, formas de diálogo com as palavras de outrem na escrita de artigos científicos produzidos por jovens pesquisadores. Fundamentados em pressupostos teóricos do Círculo de Bakhtin acerca da abordagem dialógica da linguagem e em trabalhos que discutem a escrita acadêmico-científica, analisamos um corpus composto por 10 artigos científicos produzidos por estudantes de mestrado. Os resultados indicam que, no processo de apropriação da escrita científica pelo jovem pesquisador, o diálogo com a palavra de outrem, em sua dimensão interdiscursiva, revela-se marcado, de maneira acentuada, por práticas citacionais com arranjos que, no plano da forma e do conteúdo, nem sempre são considerados aceitáveis do ponto de vista das convenções acadêmico-científicas.

Palavras-chave: Dimensão interdiscursiva; Escrita científica; Jovens pesquisadores.

Title: The interdiscursive dimension of saying in the scientific writing: the dialogue with the word of the other in scientific papers of young researchers

Abstract: Considering that researchers can carry out subtle and complex ways of elaborating the words of others (BAZERMAN, 2011) in the writing of academic-scientific texts, we intend to examine, in this study, forms of dialogue with the words of others in the writing of scientific articles produced by young researchers. Based on theoretical assumptions of the Bakhtin Circle about the dialogical approach of language and on papers that discuss academic-scientific writing, we have analyzed a corpus composed of 10 scientific articles produced by master's students. The results have indicated that, in the process of appropriation of scientific writing by the young researcher, the dialogue with the word of another in its interdiscursive dimension is marked, in a stressed way, by quotative practices with arrangements that, in terms of form and content, are not always considered acceptable from the point of view of academic-scientific conventions.

Keywords: Interdiscursive dimension; Scientific writing; Young researchers.

\footnotetext{
${ }^{1}$ Este trabalho apresenta um recorte, com modificações e revisões, de um dos capítulos analíticos da nossa tese de doutorado, intitulada Dialogismo e construção da voz autoral na escrita do texto científico de jovens pesquisadores (BESSA, 2016).

2 Doutor em Linguística e Língua Portuguesa pela Universidade Estadual Paulista Júlio de Mesquita/FCLar/Araraquara. Professor do Departamento de Letras Estrangeiras da Universidade do Estado do Rio Grande do Norte/Campus de Pau dos Ferros. Professor do Programa de Pós-Graduação em Letras (PPGL) e do Programa de Pós-Graduação em Ensino (PPGE). Orcid: http://orcid.org/0000-0003-4655-6832.

E-mail: cezinaldobessauern@gmail.com
} 


\section{Introdução}

No pensamento de Bakhtin (2003), encontra-se a formulação segundo a qual a própria ideia de todo sujeito, expressa em qualquer enunciado, nasce e forma-se no processo de interação e luta com os pensamentos dos outros. Considerando essa compreensão e levando em conta que os pesquisadores podem desenvolver "maneiras sutis e complexas de elaborar as palavras dos outros" (BAZERMAN, 2011, p. 103) na escrita de textos acadêmico-científicos, pretendemos examinar, neste trabalho, formas de diálogo com as palavras de outrem na escrita de artigos científicos produzidos por jovens pesquisadores.

Mesmo conscientes de que, nas reflexões do Círculo de Bakhtin, a presença das palavras de outrem, em todo dizer, é concebida nas duas direções mais amplas que correspondem ao funcionamento dialógico da linguagem, o encontro com o outro no objeto e o encontro com o outro na destinação, optamos ${ }^{3}$ por focalizar, especificamente, a primeira dessas direções, visando a demonstrar como a dimensão interdiscursiva do dizer revela-se um recurso enunciativo-discursivo de manejo complexo, nem sempre bem-sucedido na escrita científica de jovens pesquisadores.

Centramos nossa atenção na identificação, descrição e interpretação de formas linguísticas que indiciam o lugar do outro na constituição do dizer de jovens pesquisadores, mais precisamente de estudantes de mestrado. Para tanto, trazemos exemplos que evidenciam o funcionamento multifacetado e complexo dessas formas nos enunciados analisados. Essas formas de citar são aqui concebidas como marcas que, além de demostrar(em) o modo pelo qual o jovem pesquisador maneja o conhecimento de outras fontes, indiciam a avaliação feita das palavras citadas e denotam, também, o modo como o jovem pesquisador, na interlocução com essas palavras e fontes, constrói seu próprio dizer na escrita de artigos científicos.

Neste trabalho partimos, portanto, da compreensão de que, conforme afirma Thompson (2001), a maioria dos escritores novatos (neste caso, também os estudantes de mestrado) enfrentam consideráveis dificuldades em fazer referência à literatura, incluindo aí, evidentemente, o manejo de citações. Além disso, compartilhamos aqui da compreensão de que as dificuldades enfrentadas nesse âmbito por estudantes de mestrado estão atreladas também à complexidade que é inerente ao ato de citar na escrita de textos acadêmico-científicos. Assumimos, pois, com base em Rinck e Mansour (2013), que inserir uma citação, comentá-la, reformulá-la de maneira pertinente, discutir os autores lidos e se posicionar em um campo são competências complexas.

Tendo em vista essas compreensões e a necessidade de apresentarmos reflexões e contribuições alinhadas às posições de trabalhos que defendem um ensino mais sistemático

\footnotetext{
${ }^{3}$ Compreendemos que, no intercâmbio verbal entre os sujeitos, o movimento entre o dito e o antecipável do dizer constitui um todo inseparável e imbricado. Assim, apenas uma questão de ordem metodológica, que visa a realçar as nuances constituintes da dimensão interdiscursiva do dizer, justifica a nossa opção por focalizá-la de maneira separada da dimensão interlocutiva.
} 
e pontual das práticas citacionais na escrita de textos científicos de jovens pesquisadores, encontramos motivação para a realização deste trabalho.

\section{Ancoragens teóricas}

O recorte teórico que sintetizamos aqui compreende reflexões em duas direções: i) a abordagem dialógica da linguagem do Círculo de Bakhtin, com atenção na problemática do discurso citado/discurso de outrem; ii) a escrita na universidade, com ênfase na questão da discussão sobre gêneros discursivos e práticas de escrita.

Dialogismo e discurso de outrem na perspectiva do Círculo de Bakhtin

Neste trabalho, assumimos, como ancoragem teórico-metodológica central, pressupostos da abordagem dialógica da linguagem formulada pelo Círculo de Bakhtin. Desse modo, temos como pressuposto central a ideia de que a dialogicidade é princípio constitutivo de todo dizer, de todo ato de palavra. Na reflexão bakhtiniana, não existe palavra isolada do fluxo da cadeia de sentidos que constitui a comunicação discursiva. Logo, a palavra do sujeito que fala/escreve se constitui sempre em um fluxo corrente, dinâmico e tenso de respostas axiologicamente valoradas aos dizeres de outros sujeitos.

Conforme esse pressuposto, todo enunciado que produzimos dialoga com um já dito por outrem e antecipa possíveis respostas do(s) outro(s) para quem nos dirigimos nossas palavras sempre que enunciamos. Esse entendimento caracteriza, respectivamente, aquilo que se tem denominado de dialogismo interdiscursivo e dialogismo interlocutivo.

Associamos o dialogismo interdiscursivo ao diálogo com o já dito, ou mais precisamente, com o discurso citado, fenômeno que assume especial relevo nas reflexões do Círculo, sendo considerado o fenômeno linguístico concreto mais discutido nos textos de Bakhtin e Volóchinov (FARACO, 2009). Evidências da relevância que o tema do discurso de outrem ocupa nas reflexões do Círculo, assim como do interesse permanente de melhor compreender essa relação, podem ser encontradas em passagens de obras escritas em diferentes momentos da vida dos intelectuais do Círculo:

[...] a orientação de palavras entre palavras, as diferentes sensações da palavra outra e os diversos meios de reagir diante dela são provavelmente os problemas mais candentes do estudo metalinguístico de toda palavra, inclusive da palavra artisticamente empregada. (BAKHTIN, 2010a, p. 232)

[...] a palavra entra no enunciado não a partir do dicionário, mas a partir da vida, passando de um enunciado a outros. A palavra passa de uma totalidade para outra sem esquecer o seu caminho. Ela entra no enunciado como uma palavra da comunicação [...]. (MEDVIÉDEV, 2012, p. 185) 
[...] qualquer discurso da prosa extra-artística - de costumes, retórica, da ciência não pode deixar de se orientar para o "já dito", para o "conhecido", para a "opinião pública", etc. A orientação dialógica é naturalmente um fenômeno próprio a todo o discurso. Trata-se da orientação natural de qualquer discurso vivo. Em todos os seus caminhos até o objeto, em todas as direções, o discurso se encontra com o discurso de outrem e não pode deixar de participar, com ele, de uma interação viva e tensa. (BAKHTIN, 2010b, p. 88, grifos do autor)

Como podemos perceber, as formulações do Círculo de Bakhtin sobre o discurso de outrem dão conta de um amplo espectro das questões de uso da linguagem. Essas questões comportam, por exemplo, graus e maneiras diversas de presença da palavra outra, de distância dela, bem como os diversos meios de reação a essa palavra, de sua assimilação, enquadramento e transmissão. Se, nos textos do Círculo, uma atenção especial é dada à palavra literária, especialmente ao diálogo de vozes entre autor e herói, a reflexão bakhtiniana sobre discurso citado não se limita a esse tipo de palavra. Tal reflexão ilumina a compreensão de todo e qualquer tipo de enunciado, da prosa artística à prosa extra artística, a considerar que, para o Círculo, todo dizer está sempre orientado para as palavras do outro, reage a essas palavras, está sempre em uma interação viva e tensa com elas.

Nesse sentido, podemos depreender que o tema do discurso citado é mais complexo e extensivo que as formas de dizer mais aparentes podem representar (CASTRO, 2009), estando relacionado, por exemplo, ao fenômeno do discurso bivocal, objeto de especial interesse bakhtiniano em Problemas da Poética de Dostoiésvski. Já na terceira parte do livro Marxismo e filosofia da linguagem, por exemplo, Volóchinov (2017) contempla três esquemas principais de transmissão da palavra de outrem, quais sejam: o discurso direto, o discurso indireto e o discurso indireto livre, além das variantes do discurso direto e do discurso indireto. Mas, como destaca Ponzio (2010), o fenômeno do discurso de outrem recobre tanto as formas do diálogo explícito como do diálogo implícito.

Ponzio (2010) sintetiza os esquemas principais de transmissão da palavra alheia formulados pelo Círculo, indicando as modalidades diferentes por meio das quais o sentido da palavra outra entra em relação com o sentido da palavra que a reporta:

\footnotetext{
a) o sentido da palavra alheia coincide perfeitamente com o sentido da palavra que a reporta (imitação, superposição e combinação até a repetição papagaiesca, como certos alunos nas provas)

b) o sentido da palavra alheia é apresentado na sua autonomia, nos seus mesmos termos nos quais é expresso, bem delimitado em suas fronteiras (discurso direto)

c) o sentido da palavra alheia é analisado, interpretado, explicado, manipulado (discurso indireto). (PONZIO, 2011, p. 30).
}

Notamos aí que o encontro com a palavra de outrem se manifesta por meio de diferentes formas de transposição da palavra alheia, compreendendo processos que vão desde a sua reprodução literal à sua reformulação/reelaboração. 
Dialogando com estudiosos, como Pollet e Piette (2002), Boch e Grossmann (2002) e Bazerman (2011), que se dedicaram a examinar formas de presença da palavra de outrem na produção de sentidos, porém buscando fugir da ideia de desenvolver um estudo centrado em tipologias de citações, propomo-nos, aqui, considerar o movimento interpretativo do jovem pesquisador sobre o dizer do outro a partir de um agrupamento de formas de citar a palavra de outrem. Visando a observar como o jovem pesquisador assimila o dizer do outro e o incorpora em seu enunciado enquanto manifestação de uma compreensão responsiva, que se constrói no encontro de vozes, propomos um agrupamento que compreende um contínuo, o qual vai do eixo da reprodução literal da palavra citada ao eixo da reformulação.

Em nossa proposta de análise, esse contínuo contempla os movimentos interpretativos em três eixos e se encontra pensado da seguinte forma:

Figura 1 - representação gráfica de agrupamentos das formas de citar a palavra de outrem

$$
\text { Reprodução literal do dizer } \square \text { condensação do dizer } \square \text { reformulação do dizer }
$$

Fonte: Elaboração do autor

Essa representação gráfica permite demonstrar que o nível de exigência no trabalho interpretativo sobre o dizer do outro e de sua (re)elaboração no dizer do produtor tende a se intensificar numa escala crescente, que parte do polo da "reprodução literal" do dizer e passa pelo movimento da condensação, chegando, então, ao polo da reformulação. Tais movimentos podem ser assim descritos:

a) reprodução literal do dizer - esse eixo comporta aquelas formas de citar em que o conteúdo do dizer se apresenta com maior "fidelidade" ao texto citado, ou seja, em que o esforço de reelaboração do dizer por parte de quem cita e, por conseguinte, o comprometimento com o dizer se encontra no nível mais baixo da escala representada no gráfico. Compõe o leque de formas de citar inscritos nesse movimento o discurso citado direto, o discurso citado direto com que, alguns dos casos de modalização em discurso segundo sobre o conteúdo e de modalização em discurso segundo sobre as palavras.

b) condensação do dizer - esse eixo engloba as formas de citar por meio das quais aquele que cita se concentra em resumir o conteúdo expresso no dizer do outro ou em fazer alusão a esse dizer. Desse modo, há um esforço para compreender as ideias ditas por outrem e apresentá-las de forma sintetizada ou mediante o uso de expressões e palavras que remetam à outra fonte de dizer. As formas de citar que entram nesse movimento são a evocação e a ilhota textual. Na evocação, o produtor realiza um movimento de remeter um dizer a uma determinada fonte, sem pretender resumir o seu conteúdo, o que pressupõe um trabalho de apreensão e de 
reelaboração do dizer. Na ilhota textual, por sua vez, o produtor realiza um movimento de síntese sobre o conteúdo do dizer de outra fonte, à medida que, desse dizer, ele recorta uma ideia, um sentido, que enquadra em seu texto fazendo uso de poucas palavras ou de apenas uma, sem, porém, necessariamente reformulálas.

c) reformulação do dizer - esse eixo comporta as formas de citar que implicam um trabalho maior de reelaboração do conteúdo do dizer, considerando que exige daquele que cita um esforço maior no sentido de interpretar e de expressar uma compreensão do dito usando as "próprias palavras". As formas de citar que entram nesse movimento são o discurso citado indireto e alguns dos casos de modalização em discurso segundo sobre o conteúdo.

A modalização em discurso segundo sobre o conteúdo é enquadrada, neste trabalho, tanto no polo da reprodução literal do dizer quanto no polo da reformulação do dizer, tendo em vista que há casos, em nosso corpus, nos quais o dizer do outro é expresso segundo uma outra fonte, que se encontra demarcada mediante o uso de aspas. Além disso, há casos em que esse dizer do outro indica uma reformulação do produtor e se expressa por meio das palavras daquele que cita.

Isso posto, é importante, por fim, destacarmos que, independentemente da forma de citar mobilizada pelo sujeito que escreve, há sempre uma tomada de posição, uma relação responsiva ativa do produtor do texto, que dá um outro colorido à palavra do outro, fazendo-a ressoar de forma diferente e expressar um ponto de vista diferente, afinal, tomada na cadeia complexa da comunicação discursiva, toda e qualquer forma de transmissão da palavra alheia estará sempre permeada pelo viés valorativo do sujeito que dela faz uso.

A escrita na universidade: a propósito das especificidades de gêneros discursivos e práticas de escrita

Escrever textos na universidade tem se revelado uma prática cada vez mais rotineira na vida de professores, pesquisadores e estudantes, da graduação à pós-graduação. Os textos por eles produzidos nesse ambiente são bastante diversificados e têm fins muito específicos. Para se referirem a esses textos, estudos diversos e manuais de metodologia e/ou de escrita acadêmico-científica têm utilizado, muito frequentemente, termos como escrita científica, escrita acadêmica, escrita de pesquisa, escrita acadêmico-científica, escrita especializada, escrita profissional, texto acadêmico, gênero acadêmico, discurso acadêmico, texto da esfera acadêmico-científica, gêneros da esfera acadêmico-científica, texto de pesquisa, entre outros, que são tomados, na maioria das vezes, como equivalentes. 
Com o propósito de melhor caracterizar e definir a natureza e resguardar as especificidades desses textos, é prudente considerar o estabelecimento de uma distinção, levando em conta que, na universidade, há aqueles textos/gêneros que podem ser associados mais diretamente à prática da atividade de pesquisa e de sua divulgação. Este é o caso, por exemplo, do abstract, da resenha e do artigo científico. Há, também, aqueles que ficam mais circunscritos ao espaço de sala de aula da universidade, visando especialmente à averiguação do aprendizado do estudante em disciplinas, como ocorre com as fichas e diários de leitura, os seminários, os relatórios de estágio, os resumos, os fichamentos, certos tipos de resenhas, entre outros. Os primeiros podem ser associados ao termo científico; os segundos, ao termo acadêmico.

Em texto de sugestivo título, Textos acadêmicos e científicos: as mesmas ou diferentes comunidades?, Russel e Cortes (2012) assumem a complexidade de diferenciar os termos, todavia não deixam de apontar a distinção aqui assumida. Esses autores entendem como textos científicos aqueles produzidos por profissionais da ciência (pesquisadores, cientistas); já como textos acadêmicos, aqueles geralmente produzidos por estudantes no ensino superior, tendo normalmente como objetivo prepará-los para escrita dos textos científicos.

Delcambre (2013) se soma a essa linha de entendimento de Russel e Cortes (2010) e vai mais além, ao propor a distinção de três práticas de escrita no universo acadêmico: escrita acadêmica, escrita de pesquisa em formação e escrita de pesquisa. Ela sustenta a ideia de que a escrita acadêmica é o tipo de escrita que os estudantes praticam no universo acadêmico, cujo objetivo é a validação dos estudos. Já a escrita de pesquisa em formação e a escrita de pesquisa estão ligadas propriamente à atividade de pesquisa, de produção e divulgação do saber. $\mathrm{O}$ que, de acordo com a autora, diferencia essas duas últimas práticas de escrita são as posições dos pesquisadores em relação ao saber e aos textos do outro aos quais se reportam. Podemos melhor caracterizar essa distinção nos seguintes termos: escrita de estudantes em formação na pós-graduação e escrita de pesquisadores profissionais. A autora pontua que, embora o mémoire de máster e a tese sirvam também para validar os estudos, tais práticas se constituem, sobretudo, como escrita de pesquisa em formação.

Sob esses olhares, sustentamos a distinção aqui proposta busca ressaltar a necessidade de se levarem em conta os usos efetivos dos textos, suas finalidades comunicativas e os interlocutores que se privilegiam nas práticas comunicativas que recobrem o universo acadêmico. Desse modo consideramos, neste estudo, que um traço definidor do texto científico é a especificidade da construção e divulgação do conhecimento, numa perspectiva de compreensão de construção do conhecimento científico que não dissocia a produção do texto de sua publicação. Afinal, como nos afirma Day (2001), por mais espetaculares que sejam os resultados de uma experiência científica, ela só termina quando os resultados e as descobertas são publicados.

Não podemos esquecer que o espaço da universidade, especialmente no Brasil, é o cenário por excelência em que se desenvolvem as atividades de pesquisa e sua 
publicação/difusão (GOERGEN, 2012). Além disso, é nele em que se encontram os atores principais das cenas que compõem essas atividades. Como lembra Severino (2013), é no tecido da instituição universitária que a pesquisa se desenvolve capilarmente. Mais especificamente, é no âmbito da pós-graduação, como lugar de produção, cultivo e sistematização de conhecimento novo, que a prática da pesquisa encontra seu lugar natural, sua centralidade (SEVERINO, 2013). Por isso, jovens pesquisadores em formação na pósgraduação stricto sensu têm sido cada vez mais incentivados a produzir e a publicar textos científicos, especialmente na forma de artigo científico, que é a "prática comunicativa prototípica da atividade de pesquisa" (BOCH, 2013, p. 553).

\section{Aspectos metodológicos}

Como já mencionamos aqui, este trabalho é um recorte de nossa tese de doutorado. Portanto, a metodologia nele utilizada recupera, de forma sintetizada, a natureza da pesquisa e os procedimentos de coleta e análise do corpus apresentados no texto da tese.

Estabelecendo diálogo, sobretudo com as concepções de pesquisa de Denzin e Lincon (2006), caracterizamos a presente pesquisa, quanto à sua natureza, como interpretativa. Assumimos, pois, que, num empreendimento investigativo dessa natureza, a descrição, a análise e a interpretação como procedimentos inter-relacionados, que caracterizam como interpretativo o fazer científico, colaboram para assegurar uma compreensão em profundidade do objeto de estudo. Quanto à abordagem da pesquisa, privilegiamos o enfoque qualitativo, tendo em conta que o propósito esteve centrado em olhar para o corpus de pesquisa tentando enxergar nele os aspectos singulares do objeto, não ignorando, evidentemente, a manifestação de regularidades.

O corpus analisado constitui-se de 10 de artigos científicos produzidos por estudantes de mestrado acadêmico, das áreas de Letras e Linguística. Eles foram selecionados dos anais da VII edição do Congresso Internacional da ABRALIN, realizada em 2011, na Universidade Federal do Paraná. A escolha dos anais da referida edição tomou como critério determinante o fato de ser, no período de nossa coleta, o congresso mais recente da referida associação com anais disponíveis nos formatos de $C D-R O M$ e on-line.

Dentre os vários artigos científicos publicados nos anais do referido evento, estabelecemos como critério, dentre outros mais que se encontram no texto da tese, selecionar aqueles artigos que, em alguma medida, assumissem textualmente adotar concepções teóricas dos estudos bakhtinianos ou da teoria/análise dialógica do discurso.

Tendo em vista que, neste trabalho, consideramos pertinente caracterizar o gênero do discurso analisado em nossa pesquisa, cumpre pontuar que, em sua organização macroestrutural, os artigos científicos selecionados são, em geral, compostos das seguintes seções: introdução, fundamentação teórica, metodologia, análise dos dados e conclusão. 
Quanto à natureza, os 10 artigos científicos que compõem o corpus podem ser caracterizados, conforme classificação e definição de Motta-Roth e Hendges (2010), como artigos empíricos, tendo em vista todos eles assumem como propósito apresentar e discutir dados sobre um determinado problema e fazer interpretações na forma de resultados de pesquisa.

Por fim, é necessário indicar que o percurso analítico-interpretativo de que resultou o trabalho de pesquisa seguiu os seguintes procedimentos: a) após uma leitura exploratória inicial para conhecer cada um dos textos do corpus, no que concerne ao conteúdo e à organização textual, procedemos à realização de leitura e releitura do material, com vistas a identificar e destacar enunciados que pudessem ser interpretados como manifestações da presença da palavra de outrem; b) sistematização e agrupamento dessas manifestações em categorias analíticas; c) descrição de categorias de análise correspondentes a essas manifestações; d) seleção de fragmentos/excertos dos textos do corpus para ilustrar as categorias de análise elaboradas; e) realização de análise qualitativa do corpus, visando, principalmente, a descrever e a interpretar as manifestações da presença da palavra de outrem identificadas nos textos.

\section{Formas de manifestação do dialogismo interdiscursivo em artigos científicos de jovens pesquisadores}

Nesta seção, concentramo-nos na análise de formas de diálogo com as palavras de outrem na escrita do artigo científico produzido por jovens pesquisadores. A análise empreendida aqui se organiza em conformidade com o agrupamento de formas explícitas de citar o dizer de outrem discutidas na seção Dialogismo e discurso de outrem na perspectiva do Círculo de Bakhtin. Nesse sentido, procuramos focalizar o movimento interpretativo do jovem pesquisador sobre o dizer do outro, conforme os eixos de reprodução literal do dizer, condensação do dizer e reformulação do dizer.

Do eixo da reprodução literal do dizer, tomamos, inicialmente, o caso do discurso citado direto, e exploramos algumas nuances sobre o seu uso. Mais que "simplesmente" reproduzir literalmente um dizer, demarcando a fronteira entre a palavra de outrem e a palavra própria mediante a utilização de aspas e a indicação da fonte das palavras tomadas de empréstimo, o uso do discurso direto pode revelar diferentes e sutis maneiras de o jovem pesquisador dialogar com a palavra de outrem. Isso, por conseguinte, implica diferentes posições responsivas que o pesquisador pode assumir na construção do seu dizer, como veremos na continuidade da análise.

Assim, é necessário explicitarmos que o discurso direto se presta a cumprir diferentes finalidades dentro da argumentação científica do texto do jovem pesquisador. Em um dos extremos dos usos do discurso direto, está o caso de sua utilização com finalidade 
meramente demonstrativa, em construções linguísticas sem ruptura no plano sintático, como ilustra o seguinte excerto:

(01)

Também levando em consideração que os falantes se comunicam por textos, os exemplos retirados tanto do Orkut como das atividades escolares serão listados e enumerados, denotando seu contexto. Afinal a construção de sentido no texto é dada por alguns fatores, em seu momento de uso: "... coesão, coerência, informatividade, situacionalidade, intertextualidade, intencionalidade e aceitabilidade" $(\mathrm{KOCH}, 2004$, p. 136). (AC04, p. 4310)

No excerto 01, o trecho sublinhado assinala que o produtor se limita a transcrever os fatores de textualidade propostos por uma das autoras nas quais aquele se fundamenta em seu texto, no caso a estudiosa Koch. Não se observa, então, no posicionamento do produtor, um esforço de comentar, discutir, interpretar ou questionar a autora. Na verdade, o produtor se limita a demonstrar os fatores de textualidade que a estudiosa citada propõe. Isso mostra que a relação estabelecida pelo produtor com a voz citada é de pleno respeito à autoridade do dizer, ao ponto de levá-lo a colocar entre aspas um dizer que, nesse caso, poderia ser expresso sem o uso desse recurso ou sem uso de um discurso direto. A opção desse jovem pesquisador pode ser um indício da constatação feita por Pollet e Piette (2002, p. 171), segundo a qual os estudantes afirmam: "os outros dizem totalmente melhor que eu".

O uso do discurso direto pode se realizar também em orações integradas justapostas. Esse caso se dá quando não há um verbo introdutor de um ato de enunciação, sendo as aspas a marca decisiva que permite demarcar a fronteira entre o dizer do produtor do texto e do outro a quem ele cita. Nesses casos, o trabalho interpretativo sobre o dizer do outro pode ser de maior ou de menor intensidade, dependendo da forma como o produtor enquadra esse dizer no seu texto. No excerto que segue, esse esforço se aproxima de um nível baixo de apreensão e de interpretação do dizer do outro:

(02)

Com relação à palavra, Bakhtin (2003) afirma que a escolha desta ocorre de acordo com as especificidades do gênero discursivo escolhido no momento. Sendo o gênero uma forma típica do enunciado, no gênero a palavra incorpora tal tipicidade. "A escolha de todos os recursos linquísticos é

\footnotetext{
${ }^{4}$ Com vistas a preservar a identidade dos autores dos textos coletados em nossa pesquisa, os artigos científicos foram codificados com a seguinte identificação: AC01, ACO2, AC03 e assim por diante, sendo que AC corresponde a Artigo Científico, e os numerais cardinais $01,02,03$... correspondem à ordem numérica, estabelecida aleatoriamente, dos textos em nosso corpus. Ao longo das análises, procuramos nos referir aos autores dos artigos como produtores, para evitar qualquer conflito com a designação das vozes que eles citam em seus textos, as quais são referidas como autores, estudiosos, teóricos. Acompanhando a identificação do artigo, encontra-se ainda a indicação da página da qual foi recortado o excerto. Assim, AC04, p. 4310 indica que o fragmento em análise se trata do artigo científico do produtor 04 e foi recortado da página 4310 do referido artigo. Além disso, os destaques em itálico, negrito e sublinhado que aparecem nos excertos são de nossa responsabilidade, dado o propósito de realçarmos determinados aspectos da análise.
} 
feita pelo falante sob maior ou menor influência do destinatário e da sua resposta antecipada". (BAKHTIN, 2003, p. 306). (AC04, p. 4310)

O trecho citado que se encontra neste excerto não apresenta um esforço de leitura mais crítica ou de problematização ou mesmo de síntese do dizer do outro por parte do produtor do texto. Observa-se que, ao abordar a questão do uso de marcas linguísticas que caracterizam cada forma típica de enunciado, o produtor se fundamenta na visão de Bakhtin. Assim, ele faz referência à visão desse estudioso, em um primeiro momento, por meio de um discurso indireto, e, em um segundo momento, por meio de um discurso direto. O uso do discurso direto, nesse caso, parece configurar uma "renúncia" por parte do produtor em se expressar com as "próprias palavras", abrindo espaço para fazer enunciar um outro, isto é, uma autoridade, que, quanto à posição, é vista como inquestionável, indiscutível. Esse excerto aponta, pois, que a inserção da citação carece de um trabalho mais elaborado de articulação das ideias e/ou de seu desenvolvimento, de maneira a incorporar, por exemplo, um comentário, uma apreciação, dentre outras atitudes responsivas possíveis. Assim sendo, esse caso parece evidenciar o que Pollet e Piette (2002) denominam de justaposição de fontes, que pode ser tomada como indicação das dificuldades enfrentadas pelo jovem pesquisador no trabalho de gerenciar vozes em seu texto.

Não acreditamos, contudo, que todo procedimento de deixar falar um outro, por meio do uso de um discurso direto em orações integradas justapostas, represente uma forma malsucedida de dialogar com a palavra alheia. Pelo contrário, esse uso pode ser produtivo, dependendo, evidentemente, do modo como é enquadrado dentro do dizer do produtor do texto, de que é exemplo esse outro excerto:

(03)

Ver-se pelo espelho, pelos olhos do outro, talvez seja o mais difícil exercício decorrente da escrita que se torna pública, e é também condição para a autoria, como bem aponta Bakhtin $(2000, p$. 36) ao afirmar que o autor deve situar-se fora de si mesmo. "Ele deve tornar-se outro relativamente a si mesmo, ver-se pelos olhos do outro". Ao fazer isso, o autor se dispõe a colocar-se diante do inusitado que pode surgir de sua singularidade quando vista de outro ponto. (AC01, p. 67).

No excerto acima, tal como no excerto anterior, o produtor faz, em primeiro lugar, uso de um discurso indireto, e, em seguida, mobiliza o discurso direto. Aqui, porém, o produtor recorre ao discurso direto para comprovar a posição bakhtiniana, segundo a qual $o$ autor se situa fora de si mesmo, posição da qual o produtor compartilha e toma como ancoragem para refletir sobre o trabalho com a escrita. Nesse caso, o produtor não apenas usa o discurso direto com a finalidade de fundamentar o que havia dito sob a forma de discurso indireto. Tal postura implica, portanto, um trabalho de articulação de ideias, de vozes, e manifesta, também, um esforço para compreender e discutir o que está expresso no discurso direto, como se pode verificar no trecho que se segue à citação: Ao fazer isso, $o$ autor se dispõe a colocar-se diante do inusitado que pode surgir de sua singularidade quando vista de outro ponto. Como se trata de um artigo científico que se propõe a refletir sobre 
uma experiência de ensino, o dizer do outro funciona como uma "lente" de que se vale o produtor para compreender a experiência de que trata. Assim, a forma de dialogar com essa voz sofre a injunção do propósito do artigo e da maneira particular escolhida por seu produtor de organizar esse enunciado em sua macroestrutura textual.

Além de expressar o discurso direto em orações integradas justapostas, o jovem pesquisador faz uso desse modo de citar o dizer do outro em orações não integradas, ou seja, em estruturas de discurso citado nas quais não há marcas explícitas que caracterizam a introdução de uma citação, a não ser o afastamento da margem, como evidenciam os dois excertos que seguem:

(04)

Assim, na esfera jornalística, o lugar da ficção é, principalmente, o das crônicas. As crônicas, na fronteira entre o jornalístico e o literário, partem normalmente do factual, e estão livres para seguir por um universo fictício para a consecução do seu intuito discursivo.

Há sim, uma fronteira entre jornalismo e ficção. Mas é uma fronteira permeável, que permite uma útil e amável convivência. No passado, grandes escritores foram grandes jornalistas: o caso de Machado de Assis, de Lima Barreto. Nada impede que esta tradição tenha continuidade. (SCLIAR, 2002, p. 14).

A fição, mesmo nas crônicas, é o caminho trabalhado pelo autor para um comentário sobre uma prática da sociedade em que vive. É a "simulação" de uma possivel realidade a fim de oferecer outro olhar sobre a realidade vista pelo leitor. A própria atitude do leitor perante o texto já pressupõe a descoberta das relações da crônica com os acontecimentos da sociedade em que vive. (AC02, p. 2211).

O fato de a crônica ser parcialmente individual é pela presença do texto no jornal, o que pressupõe um encaminhamento ideológico conforme a linha editorial do veículo, apesar de ser um texto assinado.

Sendo a crônica uma soma de jornalismo e literatura (daí a imagem do narrador-repórter), dirige-se a uma classe que tem preferência pelo jornal em que ela é publicada (só depois é que irá ou não integrar uma coletânea, geralmente organizada pelo próprio cronista), o que significa uma espécie de censura ou, pelo menos, limitação: a ideologia do veículo corresponde aos interesses dos seus] consumidores, direcionados pelos proprietários do periódico e/ou pelos editores-chefes de redação. (SÁ, 1987, p. 8).

Assim, além do ponto de vista do autor, está o ponto de vista do veículo de comunicação, dado a partir de uma linha editorial a ser seguida por todo o conjunto de textos que compõem o jornal. (AC02, p. 2221-2222)

O caso ilustrado por meio desses dois excertos é particularmente interessante, porque demonstra como o sujeito jovem pesquisador situa o seu dizer numa relação com o dizer do outro de modo bem diferente daquele visto nos excertos anteriores. Aqui, o produtor se autoriza a dizer e a construir posicionamentos, conforme mostram os trechos sublinhados, sem remeter a uma fonte do empréstimo das palavras citadas, de modo a produzir um efeito de que a voz dos autores citados cumpre a função de ratificar seus "próprios" posicionamentos, quando, na verdade, tais posicionamentos devem ser atribuídos a outras fontes de dizer. Assim, o produtor tece uma trama discursiva reveladora 
de um modo de enunciar que parece indicar que ele já assimilara e monologizara a palavra de outrem, de modo a se assumir como responsável por um dizer. Se em 04 o produtor insere a citação com o único intuito de ratificar o seu dizer, em 05 ele retoma o dizer expresso no discurso citado e manifesta um movimento de interpretação que pode ser caracterizado como uma espécie de dedução do que o autor citado, no caso Sá, declara acerca dos pontos de vista que são veiculados na crônica.

O discurso direto também é usado, embora de forma mais rara, para marcar uma relação dialógica mais tensa entre o dizer do jovem pesquisador e o do outro que ele cita. Isso se dá quando o produtor retoma um dizer sob a forma de discurso direto para, em seguida, discuti-lo ou problematizá-lo, quando não para expressar uma discordância, enquanto expressões de sua apreensão ativa do discurso de outrem. No excerto a seguir, temos um caso em que o produtor discute e problematiza o dizer do outro:

(06)

No que concerne à intergenericidade, Fix (2006) tem um dos trabalhos precursores. A linguista alemã argumenta que o cânone e a dissolução do cânone, típicos do comportamento das sociedades, está se refletindo nos textos com mais frequência. Logo, textos publicitários (sejam políticos, sejam comerciais), jornalísticos, aforismos, pichações etc., por terem a característica de chamar a atenção do público, "são formados com recursos da dissolução do cânone: variações, montagens de texto, transgressões $e$ misturas textuais e estilísticas" (FIX, 2006, p. 264). Para esta variação, a autora atribui a nomenclatura "intertextualidade tipológica". Então,

uma montagem de padrões de textos poderia ser descrita como um acoplamento de vários exemplares de textos que pertencem, cada um, a outro tipo de padrão, mas que seguem uma única intenção textual. [...] Uma transgressão de padrões de textos ocorre quando um exemplar de texto tem as características de um padrão de texto e, além disso, traços que não podem ser associados, inequivocamente, com nenhum padrão de texto (FIX, 2006, p. 264).

Logo, para a autora, qualquer tipo de mescla, transgressão de regras ou apagamento de fronteiras leva à "dissolução do cânone". Essa quebra de paradigmas, na verdade, representa um recurso estilístico dos textos, elaborados de tal forma criativa que permita chamar a atenção dos leitores. Então todas essas transgressões da regra são fabricadas para levar a um objetivo específico.

Embora concordemos com todo o posicionamento da autora, são limitados os exemplos trazidos por ela, pois todos trazem uma mescla envolvendo sempre um padrão de um determinado gênero e um padrão de outro gênero, sendo que um deles é voltado para o nível da forma/estrutura. Além disso, ao adotar a expressão "intertextualidade tipológica", ela não deixa claro como se dá essa relação entre textos. Temse, sim, a forma de um gênero e o conteúdo/propósito comunicativo de outro, ou seja, nem sempre há uma relação entre textos diretamente. Fica a dúvida de que conceito de intertextualidade a autora se utiliza também para chegar a essa nomenclatura. (AC03, p. 4355-4366)

Concentrando-nos mais particularmente no dizer do produtor que se segue à segunda ocorrência de discurso direto no excerto acima, é possível perceber como o produtor do artigo responde ao dizer da autora citada, expressando, em relação a ele, um tom de questionamento e de problematização. Observa-se aí que há, inicialmente, um esforço por parte do produtor na tentativa de sintetizar a posição de Fix sobre o fenômeno da intertextualidade tipológica, como comprovam os dizeres expressos no primeiro parágrafo que segue à segunda citação, para, em seguida, apontar que concorda com a 
autora, mas que considera (o que revela um índice da apreciação pessoal) limitados os exemplos de intertextualidade tipológica apresentados pela autora citada. O produtor continua sua problematização do dizer da autora, sustentando que ela não deixa claro como se dá relação entre textos, quando adota a expressão "intertextualidade tipológica", e, por fim, questionando que conceito de intertextualidade a autora utiliza para chegar à nomenclatura empregada. Percebemos, assim, que o produtor busca se posicionar de modo mais crítico em relação ao dizer que cita, inclusive mantendo uma relação "menos respeitosa" com o autor citado, no sentido de colocar sob questão posições assumidas por uma autora considerada autoridade no assunto abordado.

Uma forma de posicionamento mais incisiva ainda, do ponto de vista da distância crítica que o produtor assume, se configura quando ele discorda explicitamente do dizer de outrem, expressando-se sob a forma de discurso direto, tal como se dá no excerto a seguir, recortado também de $\mathrm{ACO3}$ :

(07)

Talvez o conceito de texto e, por consequência, o de intertexto tenham de ser reavaliados permitindo que outros elementos semióticos sejam contemplados ao conceito.

Cavalcante (2007, p. 1) lança uma proposta dessa natureza:

Assim, não importa qual o tipo de remissão - se ao léxico, se a estruturas fonológicas, a estruturas sintáticas, ao gênero, ao estilo, ao tom -, haverá intertextualidade sempre que, intencionalmente, $o$ enunciador estabelecer um diálogo entre o texto que está produzindo e outro(s), supondo que o coenunciador conseguirá reconhecer a interseção entre eles, ou seja, que será capaz de identificar o intertexto.

\footnotetext{
Mesmo assim, não fica claro qual é o intertexto numa relação intergenérica. Se dissermos, com Cavalcante (2007), que o intertexto é um elemento que permite fazer uma remissão não importa de que natureza - inclusive a gêneros - estaremos reduzindo gênero a texto.

o que queremos dizer é que, para que se mantenha operante a expressão intertextualidade intergenérica é necessário o alargamento do conceito de texto e, por conseguinte, o de intertexto, que pode ser entendido como qualquer elemento que possibilite fazer referência a outro texto ou a outro gênero, e não somente à materialidade verbal. Numa relação intergenérica, o intertexto pode ser a estrutura composicional, o conteúdo temático ou até mesmo o estilo (AC03, p. 4356-4357)
}

Se os dizeres do produtor, antes de inserir o discurso direto, não assumem, de modo categórico, que os conceitos de texto e de intertexto tenham que ser reavaliados, suas palavras, após a citação de Cavalcante, expressam uma posição de discordância em relação ao pensamento dessa autora. Logo, o produtor entende que a compreensão de intertexto sustentada por Cavalcante reduz gênero a texto e, também, que a posição da referida estudiosa não explicita a incorporação de elementos semióticos em uma relação intertextual. Nesse caso, o produtor procura estabelecer um diálogo com uma estudiosa da temática da intertextualidade, que se encontra situada em outro lugar teórico (no caso, a Linguística Textual), em cujas posições aquele busca respaldo para entender a intertextualidade intergenérica, fenômeno que tem sido situado no âmbito dos estudos de gêneros numa perspectiva Sociorretórica. Ainda que encontre, nos estudos de Cavalcante, elementos para entender o fenômeno da intertextualidade intergenérica, o produtor se 
posiciona mais precisamente expressando uma discordância em relação às posições da autora, demonstrando, assim, uma distância crítica quanto aos dizeres citados.

Em relação ao eixo da condensação do dizer, observamos os casos de evocação e de ilhota textual. Partindo da evocação, é pertinente sublinhar que, nesta, podem-se revelar algumas características como, por exemplo, sintetizar uma ideia do dizer de outrem expresso com maior ou menor esforço de interpretação por parte do produtor.

Com menor esforço interpretativo, ocorre, por exemplo, quando o produtor situa o seu objeto de estudo ou a metodologia do seu trabalho dentro de uma determinada corrente teórico-metodológica, à qual faz referência, sinalizando uma ideia mais geral, sem, porém, desenvolver, naquela seção do texto, o conteúdo do dizer, como constatamos no exemplo a seguir:

(08)

\subsection{CONSTITUIÇÃO DO CORPUS}

O corpus vai se constituindo à medida que avançamos na nossa análise e os procedimentos utilizados, fazem parte também da constituição do corpus. A nossa orientação teórica a qual vê a linguagem como prática social, norteada pelos pressupostos de Bakhtin, é base para a nossa analise. (AC06, p. 965)

Nesse excerto, recortado de um segmento da seção de metodologia do artigo, vemos que o produtor faz uso da evocação com a finalidade de explicitar/sinalizar a orientação teórica que fundamenta a análise do corpus da pesquisa. Observamos que o produtor se limita a sinalizar a concepção de linguagem e relacioná-la a uma determinada fonte, no caso a perspectiva dos estudos de Bakhtin, que é a ancoragem teórica referida como sustentação da análise.

Usos semelhantes ao ilustrado em 08 costumam ocorrer na seção de introdução, quando o produtor mobiliza uma evocação para fazer referência aos autores ou a uma corrente teórica que fundamentará seu trabalho, cujos pressupostos (conceitos, categorias de análises, posições teóricas) são retomados em outras seções do trabalho, seja na fundamentação teórica, seja na análise, seja, por fim, na conclusão, de que é exemplo o caso do excerto 09:

(09)

A abordagem teórica de Bakhtin (2003), no que se refere ao conceito de gênero discursivo, transmutação e análise feita das marcas de transmutação, permitiu que o artigo atribuísse ao scrap o status de gênero emergente da mídia digital. (AC04, p. 4306)

Com manifestação de maior esforço interpretativo, o uso da evocação se dá quando o produtor sintetiza a ideia de um determinado autor com o propósito de problematizar seu objeto de estudo, como mostrado no excerto 10, caso em que podemos verificar um trabalho do produtor no sentido de reelaborar ideias, informações e concepções e articular pontos de vista, autores, correntes teóricas, na defesa de uma linha argumentativa. 
(10)

O olhar de preocupação para com a escrita de textos acadêmicos produzidos por estudantes universitários tem ocupado a atenção de um grande número de estudiosos da linguagem, que têm apontado, reiteradamente, para as dificuldades que esses estudantes apresentam na escritura de textos dessa natureza, seja em seguir a orientação argumentativa do texto-base e efetivar o gerenciamento de vozes em atividades de retextualização (MATÊNCIO, 1997); seja em inscrever o apoio no discurso do outro na escrita de relatórios de pesquisa (BOCH, GROSSMANN, 2001), seja no estabelecimento da coerência local em relatórios de estágio, advinda da ausência de articulação de sentido entre título e os segmentos (parágrafos) que constituem o conteúdo do texto (RODRIGUES, 2003), seja em praticar a condensação ou síntese, a explicitação, explicação e mesmo a exemplificação de idéias no trabalho de parafraseamento (BERNARDINO, 2009), entre outros aspectos, o que mostra quão problemático tem sido o trabalho com a escrita de textos acadêmicos no ensino superior. (AC08, p. 2068-2069)

Em casos como esse, recortado da seção de introdução de um dos artigos analisados, nem sempre as ideias, as concepções, os pontos de vista, os autores e as correntes teóricas a que o produtor faz referência são necessariamente retomadas nas seções posteriores à introdução. Muitas das vozes evocadas, nesses casos, fazem parte do esforço do produtor em mostrar que existe um problema de pesquisa e, também, para demonstrar o que já se sabe acerca da temática, demarcando e, sobretudo, justificando sua proposta de investigação.

A propósito da ilhota textual, podemos destacar, como o seu uso nos textos analisados sinaliza, uma maneira do funcionamento complexo do diálogo com o dizer do outro, dado o modo como o produtor assimila e "manipula" as palavras de outrem na construção de seu dizer. Isso significa afirmar que, no trabalho de apreensão do dizer do outro, o produtor recorta palavras e as enquadra em seu projeto de dizer com diferentes orientações de sentido e finalidades, as quais nem sempre indicam um uso pertinente e apropriado desse recurso.

Em outros casos de manifestação de ilhota textual, observamos que o produtor pode querer sugerir a presença de um outro, como consta em (11), ou pode querer se apropriar das palavras do outro como expressão de que assume o pertencimento de tais palavras, conforme vemos no excerto (12):

(11)

Com base nos princípios do dialogismo bakhtiniano, a Análise do Discurso francesa, principalmente nas obras de Osvald Ducrot, Dominique Maingueneau e Authier-Revuz, propõe o princípio da heterogeneidade, a ideia de que a linguagem é heterogênea, ou seja, o discurso é tecido a muitas vozes, pelo "já dito".

Todos os discursos são, portanto, "atravessados", "ocupados", "habitados" pelo discurso do outro. Daí a noção de que a fala é constitutivamente heterogênea, pois, na teoria bakhtiniana: "É impossivel pensar no homem fora das relações que o ligam ao outro" (BAKHTIN, 1992, p. 35-36) (AC05, p. 200)

É relevante notar, inclusive, que o Círculo de Bakhtin, muito antes de Marcuschi, portanto, também trouxe, embora não profundamente, a ideia de que os gêneros desenvolvem funções sociocognitivas. Medvedev (19284 apud FARACO, 2003), ao criticar a noção de gênero na perspectiva formalista, a qual reduz à forma o reconhecimento do gênero, desenvolve uma linha argumentativa em função da relativa 
estabilidade dos gêneros, publicada em 1953 por Bakhtin, mas já discutida ainda na década de 1920 pelo Círculo.

Pela sua estabilidade, eles são elementos organizadores das atividades e, por isso, orientam nossa participação em determinada esfera de atividade (eles balizam nosso entendimento das ações dos outros, assim como são referência para nossas próprias ações). Ao gerarem novas expectativas de como serão as ações, eles nos orientam diante do novo no interior dessas mesmas ações: auxiliamnos a tornar o novo familiar pelo reconhecimento de similaridades e, ao mesmo tempo, por não terem fronteiras rígidas e precisas, permitem que adaptemos sua forma às novas circunstâncias. (FARACO, 2003, p. 115).

Medvedev, então, por entender que os gêneros também são formas de representação da realidade, enxerga que eles são plásticos e maleáveis, pois variam de acordo com as exigências a novas situações comunicativas. Então, como cada situação comunicativa não poderá suscitar um novo gênero, estes se transformam, gerando um outro ou modificando-se a partir de gêneros já existentes. Daí o fato de o interlocutor "tornar novo o familiar", pois, como o gênero também é sócio-histórico, os interactantes da comunicação já têm em sua mente gêneros internalizados que podem ser recuperados a depender do contexto comunicativo. "Pode-se dizer que a consciência humana dispõe de uma série de gêneros internalizados para ver e conceitualizar a realidade" (MEDVEDEV, 1928 apud FARACO, 2003, p. 116). (AC03, p. 4353-4354)

Esses dois excertos que, no texto científico do jovem pesquisador, ilustram os usos de ilhota textual apontam movimentos de apreensão do discurso outro que refletem um trabalho de manipulação sobre a palavra de outrem. No excerto 11, há duas passagens que caracterizam manifestação de ilhota textual. Na primeira delas, o uso, entre aspas, do termo já dito, no trecho o discurso é tecido a muitas vozes, pelo "já dito", assinala a presença de, pelo menos, uma voz outra no dizer do produtor. Nesse caso, esse dizer, que, no texto do produtor, é atribuído à corrente dos estudos da linguagem denominada de Análise do Discurso francesa, pode ter sido assimilado de qualquer um dos autores relacionados à referida corrente que foram mencionados, podendo também ter sido assimilado de todos eles e ainda da leitura do dialogismo bakhtiniano, uma vez que, ainda de acordo com o produtor, os princípios do dialogismo fundamentam a ideia de que a linguagem é heterogênea como sustentada pela Análise do Discurso francesa. Parece-nos, assim, que esse exemplo manifesta um enunciado em que o dizer se constitui como prolongamento e cruzamentos de fios dialógicos de várias vozes que se deixam mostrar na superfície textual, cuja fonte do dizer não é, porém, passível de identificação, a não ser atribuindo-se genericamente à referida corrente teórica.

Na segunda passagem, o uso, entre aspas, dos termos "atravessados", "ocupados" e "habitados", no fragmento Todos os discursos são, portanto, "atravessados", "ocupados", "habitados" pelo discurso do outro, aponta a dificuldade em saber exatamente a que fonte de dizer o produtor se reporta. Mesmo que o autor introduza esses fragmentos de dizer em um contexto enunciativo no qual se discutem princípios do dialogismo formulados por Bakhtin, é possível deduzir que esses fragmentos sejam, provavelmente, uma influência da voz de Authier-Revuz. Ou seja, a apropriação desses termos por parte do produtor se dá, certamente, a partir dos textos de Authier-Revuz. Isso parece indicar ou uma leitura de Bakhtin, com base em Authier-Revuz, ou uma demonstração de que o produtor aproxima a 
visão de discurso de Bakhtin da visão de discurso de Authier-Revuz, sinalizando, assim, as configurações complexas do tecido de vozes na constituição do dizer do jovem pesquisador.

Em (12), por sua vez, o fragmento "tornar novo o familiar", que caracteriza a ilhota textual no enunciado Daí o fato de o interlocutor "tornar novo o familiar", pois, como o gênero também é sócio-histórico, os interactantes da comunicação já têm em sua mente gêneros internalizados que podem ser recuperados a depender do contexto comunicativo, remete não só a uma outra fonte de dizer, mas também ao dizer de um autor (Faraco), que o produtor já havia citado de forma literal no seu texto. Se, ao recortar o fragmento "tornar novo o familiar", o produtor opta por não realizar a operação de designar explicitamente a fonte do dizer, não é simplesmente pelo fato de que, no contexto e naquele contexto, o leitor poderia recuperar que aquelas palavras remetem a Faraco, mas pelo fato de que, intencionalmente, o produtor passa a assumir a pertença daquele fragmento. Com isso, temos aí um caso em que, no dizer do produtor, se confundem dois enunciados, dois modos de se expressar, duas perspectivas semânticas e axiológicas. (BAKHTIN, 2010b).

Do eixo da reformulação do dizer, observar-se-ão os usos tanto do discurso indireto quanto da modalização em discurso segundo sobre o conteúdo. É importante considerar que, quando se considera o aspecto da reformulação do dizer, logo se pressupõe uma maior autonomia por parte do produtor do texto (POLLET; PIETTE, 2002), já que implica reescrever as ideias do outro, sintetizá-las, avaliá-las e manipulá-las, apresentando as palavras expressas pelo outro sob o filtro daquele que cita. Sendo assim, o diálogo com a palavra do outro, quando expresso sob a forma de discurso indireto ou do tipo de modalização em discurso segundo sobre o conteúdo, em que o produtor visa a reformular o dizer, pressupõe um maior esforço de interpretação e de trabalho analítico sobre o dizer do outro por parte do produtor, embora existam casos em que esse esforço interpretativo seja mínimo ou mesmo quase inexistente, a depender, por exemplo, da extensão do dizer reformulado e/ou a ser reformulado.

Um menor esforço interpretativo pode ser observado, por exemplo, quando o discurso indireto se limita a "traduzir" o dizer do outro. Logo, o espaço para reformulação do dizer do outro é mínimo, como constatado em AC01. Para melhor demonstrar esse aspecto e observar o trabalho interpretativo do produtor sobre as palavras do outro, colocamos lado a lado, em um quadro, o dizer do produtor do AC01 e a palavra de outrem que é citada, aqui tomada como texto-fonte:

(13)

\begin{tabular}{|c|c|}
\hline Texto de AC01 & Texto-fonte - Brait (2006) \\
\hline $\begin{array}{l}\text { Ou seja, o estilo se faz pelas opções e escolhas do } \\
\text { autor. Por outro lado, Brait não se limita a essa } \\
\text { conceituação e sugere, orientada pelo pensamento } \\
\text { de Bakhtin, que a concepção de dialogismo } \\
\text { enquanto aspecto constitutivo dos processos }\end{array}$ & $\begin{array}{l}\text { Esse ponto de partida, ainda que estejamos omitindo a } \\
\text { sequência completa em que a construção da idéia de } \\
\text { estilo vai aparecendo, deixa claro que a concepção } \\
\text { dialógica de linguagem, a concepção de dialogismo } \\
\text { como aspecto constitutivo dos processos que envolvem a }\end{array}$ \\
\hline linguísticos está também na base na concepção & linguagem está na base também da concepção de estilo. \\
\hline de estilo. (AC01, p. 65-66). & Essa relação constitutiva entre interlocutores e entre os \\
\hline
\end{tabular}


discursos que atravessam os enunciados pronunciados ou não por esses interlocutores já está na gênese da concepção de estilo, reiterando mais uma vez a coerência desse pensamento. (BRAIT, 2006, p. 58-59).

Os trechos destacados em itálico nos dois fragmentos que compõem o excerto acima explicitam claramente que, entre o dizer do produtor e da voz que ele cita (no caso, a estudiosa Beth Brait), há uma forte correspondência, tanto no plano do sentido como da forma. Pode-se dizer que, em seu texto, o produtor se limita a realizar uma operação de substituição de termos/palavras (como aspecto constitutivo por enquanto aspecto constitutivo e processos que envolvem a linguagem por processos linguísticos) sem demonstrar qualquer esforço de operar uma reformulação que reflita uma maneira mais pessoal de dizer como ele compreende a concepção de dialogismo sobre a qual discorre.

O aspecto da forte dependência do produtor em relação à construção enunciativa dos autores citados em seu texto está presente também em formas de citar como a modalização em discurso segundo sobre o conteúdo, mais precisamente naqueles casos de modalização em que o produtor constrói um enunciado com o propósito de reformular o dizer do outro que ele cita, como é o caso abaixo:

(14)

\begin{tabular}{|c|c|}
\hline Texto de AC04 & Texto-fonte - FIORIN (2008) \\
\hline $\begin{array}{l}\text { [...] Nessa perspectiva, como afirma Fiorin (2008), } \\
\text { os gêneros são meios de apreender a realidade. }\end{array}$ & $\begin{array}{l}\text { Os gêneros são meios de apreender a realidade. } \\
\text { Novos modos de ver e de conceptualizar a realidade }\end{array}$ \\
\hline Novos modos de ver e de conceptualizar a realidade & implicam o aparecimento de novos gêneros e a \\
\hline implicam o aparecimento de novos gêneros $e$ a & alteração dos já existentes. Ao mesmo tempo, novos \\
\hline alteração dos já existentes. Ao mesmo tempo, novos & gêneros ocasionam novas maneiras de ver a \\
\hline gêneros ocasionam novas maneiras de ver a & realidade. A aprendizagem dos modos sociais de fazer \\
\hline realidade. A aprendizagem dos modos sociais de & leva, concomitantemente, ao aprendizado dos modos \\
\hline $\begin{array}{l}\text { fazer leva, concomitantemente, ao aprendizado dos } \\
\text { modos sociais de dizer os gêneros; [...] (ACO4, p. }\end{array}$ & sociais de dizer, os gêneros; [...] (FIORIN, 2008, p. 69). \\
\hline
\end{tabular}

Este caso difere pouco do que constatamos no excerto anterior. Comparando os dois fragmentos destacados com o sublinhado, fica evidente que há uma reprodução literal do dizer de Fiorin, estudioso da linguagem citado. Embora o produtor sinalize, no início do parágrafo, que enuncia segundo a fonte, que é Fiorin, e não mediante o uso de um discurso citado direto, todo o trecho sublinhado poderia/deveria ter sido reformulado, considerando que o produtor não sinaliza, com o uso de aspas, a parte tomada de empréstimo, tampouco indica a página do texto de onde foi recortado o trecho citado. Assim, o trecho citado revela plena equivalência no plano dos sentidos e da forma, sinalizando, portanto, a dificuldade do produtor de se descolar das palavras do autor do texto lido e citado.

Os casos analisados aqui mostram, em linhas gerais, o modo como, nos textos dos jovens pesquisadores, o diálogo com a palavra de outrem, em sua dimensão interdiscursiva, se caracteriza por uma variedade de modos de citar a palavra de outrem. Essa variedade se 
deixa caracterizar também pelas maneiras complexas e sutis por meio das quais o estudante de mestrado assimila e incorpora o dizer do outro em seu texto.

\section{Conclusão}

Assumindo a dimensão complexa e multifacetada do citar na escrita científica e partindo do pressuposto de que os estudantes em formação em pesquisa na pós-graduação enfrentam dificuldades de manejar adequadamente a palavra de outrem nos textos que produzem, este trabalho teve como objetivo examinar formas de diálogo com as palavras de outrem na escrita de artigos científicos de estudantes de mestrado, visando a demonstrar de que modo o diálogo com a palavra de outrem se revela um recurso enunciativo-discursivo de manejo complexo, nem sempre bem-sucedido na escrita desses estudantes.

Reportando-nos ao pensamento do Círculo de Bakhtin sobre o dialogismo no funcionamento da linguagem e a estudos que discutem a escrita acadêmico-científica, com ênfase naqueles que se dedicam à investigação sobre as formas de citar a palavra de outrem, analisamos um corpus constituído por 10 artigos científicos produzidos por estudantes de mestrado da área de Letras e Linguística.

O exame dos 10 artigos recortados indica que os estudantes de mestrado mobilizam a palavra de outrem utilizando estratégias complexas e variadas, revelando, contudo, procedimentos que tendem muito mais para a reprodução literal de palavras, inclusive quando sinalizam que estão realizando procedimentos de condensação ou de reformulação de dizeres, do que para um trabalho de reelaboração das ideias das fontes citadas.

Os resultados apontam que as diferentes formas examinadas de dialogar com a palavra de outrem confirmam a dimensão complexa que recobre os procedimentos formais do discurso citado na escrita científica dos jovens pesquisadores. Foi possível percebermos formas de citar que indicam tanto um trabalho mais cuidadoso e produtivo de reelaboração das palavras de outrem quanto procedimentos de "reprodução" e "manipulação" dessas palavras, inclusive sem atribuição formal da fonte. Esses achados demonstram o recurso a práticas citacionais com arranjos, que, no plano da forma e do conteúdo, nem sempre são considerados aceitáveis do ponto de vista das convenções acadêmico-científicas. Demonstram, ainda, o manejo, também complexo e multifacetado, dessas formas por jovens pesquisadores, em seu processo formativo na pesquisa, para construir sua voz autoral no diálogo travado com as vozes dos autores/estudiosos aos quais se reportam.

Esses resultados demonstram, portanto, a necessidade de pensarmos e avançarmos na proposição de intervenções que deem conta de oferecer formação voltada para um uso mais pertinente e produtivo de formas de citar nos textos científicos produzidos pelos jovens pesquisadores. Nessa direção, pontuamos que seja dada uma atenção ao desenvolvimento de estratégias e atividades, no âmbito da formação na pós-graduação, que favoreçam um 
trabalho que explore, de maneira orientada, mais sistemática e dinâmica, a síntese, a seleção e a reformulação de ideias de fontes mobilizadas.

Por fim, destacamos que não é prudente aceitar que, em face da conjuntura de exigências de produção que acompanha a formação do pesquisador na pós-graduação, não sejam pensadas ações (disciplinas, orientações e cursos, por exemplo) que possam colaborar e potencializar efetivamente o domínio das formas de dialogar com as palavras de outrem, em sua riqueza e complexidade, nas práticas escriturais de textos científicos dos jovens estudantes pesquisadores.

\section{Referências}

BAKHTIN, M. Estética da criação verbal. Tradução do russo de Paulo Bezerra. 4. ed. São Paulo: Martins Fontes, 2003.

BAKHTIN, M. Problemas da poética de Dostoiévski. Tradução do russo de Paulo Bezerra. 5. ed. Rio de Janeiro: Forense Universitária, 2010a.

BAKHTIN, M. Questões de literatura e de estética: a teoria do romance. Equipe de tradução Aurora Fornoni Bernardini, José Pereira Júnior, Augusto Góes Júnior, Helena Spryndis Nazário e Homero Freitas de Andrade. 6. ed. São Paulo: Hucitec, 2010b.

BAZERMAN, C. Gênero, agência e escrita. Organização de Ângela Paiva Dionísio e Judith Chambliss Hoffnagel com tradução e adaptação de Judith Chambliss Hoffnagel. 2. ed. São Paulo: Cortez, 2011.

BESSA, J. C. R. Dialogismo e construção da voz autoral na escrita do texto científico de jovens pesquisadores. 2016. 385 f. Tese (Doutorado em Linguística e Língua Portuguesa) Universidade Estadual Paulista “Júlio de Mesquita Filho", Araraquara, 2016.

$\mathrm{BOCH}, \mathrm{F}$. Former les doctorants à l'écriture de la thèse en exploitant les études descriptives de l'écrit scientifique. Linguagem em (Dis)curso, v. 13, n. 3, p. 543-568, set./dez. 2013. https://doi.org/10.1590/S1518-76322013000300005

BOCH, F.; GROSSMANN, F. Referir-se ao discurso do outro: alguns elementos de comparação entre especialistas e principiantes. Scripta, v. 6, n.11, p. 97-108, 2002.

CASTRO, G. de. Formas sintáticas de enunciação: o problema do discurso citado no Círculo de Bakhtin. BRAIT, Beht (Org.). Bakhtin e o Círculo. São Paulo: Contexto, 2009. 117-135.

DAY, R. A. Como escrever e publicar um artigo científico. Tradução de Marina André de Alvarez. 5. ed. São Paulo: Livraria e Editora Santos, 2001.

DELCAMBRE, I. Le mémoire de master: ruptures et continuités. Points de vue des enseignants, points de vue des étudiants. Linguagem em (Dis)curso, v. 13, n. 3, p. 569-612, set./dez. 2013. https://doi.org/10.1590/S1518-76322013000300006

DENZIN, N. K.; LINCON, Y. S. A disciplina e a prática da pesquisa qualitativa. In: DENZIN, N. K.; LINCOLN, Y. S. Planejamento da pesquisa qualitativa: teorias e abordagens. Tradução de Sandra Regina Netz. Porto Alegre: Artmed, 2006. p. 15-41. 
FARACO, C. A. Linguagem \& diálogo: as ideias linguísticas do círculo de Bakhtin. Curitiba: Parábola Editorial, 2009.

GOERGEN, P. A internacionalização dos programas de pós-graduação. Revista Espaço Pedagógico, v. 19, n. 2, p. 247-257, jul./dez. 2012.

MEDVIÉDEV, P. N. O método formal nos estudos literários: introdução crítica a uma poética sociológica. Tradução de Ekaterina Vólkova Américo e Sheila Camargo Grillo. São Paulo: Contexto, 2012.

MOTTA-ROTH, D.; HENDGES, R. H. Produção textual na universidade. São Paulo: Parábola Editorial, 2010.

POLLET, M. C.; PIETTE, V.. Citation, reformulation du discours d'autrui. Une clé pour enseigner l'écriture de recherche ? Spirale, n. 29, p. 165-179, 2002. https://doi.org/10.3406/spira.2002.1443

PONZIO, A. Problemas de sintaxe para uma linguística da escuta. In: BAKHTIN, Mikhail. Palavra própria e palavra outra na sintaxe da enunciação e $A$ palavra na vida e na poesia: introdução ao problema de poética sociológica. Organização e tradução aos cuidados de Valdemir Miotello e et. al. São Carlos: Pedro \& João editores, 2011. p. 7-57. https://doi.org/10.1590/S2176-45732012000100016

PONZIO, A. Procurando uma palavra outra. Tradução aos cuidados de Valdemir Miotello, Regina Silva, Daniela M. Mondardo, Camila Caracelli Scherma, Marina Haber de Figueiredo, Ana Beatriz Dias e Allan Pugliese. São Carlos: Pedro \& João editores, 2010.

RINCK, F.; MANSOUR, L. Littératie à l'ère du numérique: le copier-coller chez les étudiants. Linguagem em (Dis)curso, v. 13, n. 3, p. 613-637, set./dez. 2013. https://doi.org/10.1590/S1518-76322013000300007

RUSSEL, D. R.; CORTES, V. Academic and scientific texts: the same or different communities. In: CASTELLO, M.; DONAHUE, C. (Eds.). University writing - selves and texts academic societies studies in writing (Studies in Writing, volume 24). Emerald Group Publishing Limited, 2012. p.3-18.

SEVERINO, A. J. Ensino superior: lugar da escrita no e da produção do conhecimento. In: RIOLFI, C. R.; ALMEIDA, S.; BARZOTTO, V. H. (Org.). Leitura e escrita: impasses na universidade. São Paulo: Paulistana, 2013. p. 63-72.

THOMPSON, P. Loooking at citations: using corpora in english for academic purposes. Language Learning \& Technology, v. 5, n. 3, 91-105, 2001.

VOLÓCHINOV, V. Marxismo e filosofia da linguagem: problemas fundamentais do método sociológico da linguagem. Tradução de Sheila Grillo e Ekaterina Vólkova Américo. São Paulo: Editora 34, 2017. 